\title{
Color Analysis and Image Processing Applied in Agriculture
}

\author{
Jesús Raúl Martínez Sandoval, \\ Miguel Enrique Martínez Rosas, \\ Ernesto Martínez Sandoval, \\ Manuel Moisés Miranda Velasco and \\ Humberto Cervantes De Ávila
}

Additional information is available at the end of the chapter

http://dx.doi.org/10.5772/intechopen.71539

\begin{abstract}
Color and appearance are perhaps the first attributes that attract us to a fruit or vegetable. Since the appearance of the product generally determines whether a product is accepted or rejected, measuring the color characteristics becomes an important task. To carry out the analysis of this key attribute for agriculture, it is recommended to use an artificial vision system to capture the images of the samples and then to process them by applying colorimetric routines to extract color parameters in an efficient and nondestructive manner, which makes it a suitable tool for a wide range of applications. The purpose of this chapter is to give an overview on recent development of image processing applied to color analysis from horticultural products, more specifically the practical usage of color image analysis in agriculture. As an example, quantitative values of color are extracted from Habanero Chili Peppers using image processing; the images from the samples were obtained using a desktop configuration of machine vision system. The material presented should be useful for students starting on the field, as well as for researchers looking for state-of-the-art studies and practical applications.
\end{abstract}

Keywords: color analysis, color evolution, feature extraction, image processing, Habanero chili, computer vision

\section{Introduction}

The color assessment of fruits and vegetables in the food industry and agriculture using machine vision and image processing has become a trend in the recent years [1-3]. The color 
features are one of the key parameters to define the quality of an agricultural product $[4,5]$. The color is probably the first factor that consumers use to determine the appearance of a product [6]; appearance is a subjective factor that leads the consumer to accept or reject a food product [7]. This significantly affects the sales and profits of the industry. Therefore, a considerable effort has been made in the area of automation to improve the quality of agricultural products in the food industry in order to decrease losses.

Building machines with the ability to see color as it does the human being has been a complex task for the scientific community and industry in recent years [8-12]. Among the many challenges to be addressed, we can include appropriate image acquisition systems, lighting problems, color space definitions, mathematical issues, and the development of specific algorithms and synchronization tasks [13]. However, improvements in semiconductors, electronics, and software eventually brought the opportunity to implement image processing and colorimetric projects for various applications [11, 14, 15].

A machine vision system for horticulture products requires the ability to capture process and analyze color images, where algorithms are suitable to detect, extract, and quantify the attribute of color as much as a customer does. Furthermore, other parameters (size, texture, external blemishes, and diseases) are important to determine the appearance, and hence the quality, of an agricultural product [16-18]. This variety of applications is possible due to the interaction of light in the range of visible spectrum $(400-700 \mathrm{~nm})$ with the matter that the light can be reflected, transmitted, or absorbed by an object. The light wavelengths received by our eyes are then interpreted by our brain as color.

Perception of color, in humans, is a psychophysical phenomenon that involves three elements: the illuminant, an object, and the observer [19]. The illuminant has the function to irradiate the object with light in the visible spectrum. The object absorbs, transmits, and reflects the light received from the illuminant. The observer perceives the reflected light from the object in the retina and responds to that stimulus generating an electric signal in the optic nerve toward the brain [20]. As this phenomenon takes place in the brain, the process is an important challenge, because machine vision systems need to emulate these three elements, in a proper way, without including the real observer, the eye, and the natural illuminant, the sun [21].

A machine vision system acquires, processes, and analyzes images, and the proper operation of the system requires adequate capture conditions for the specific application. Basic machine vision components are: (a) image sensor (charge-couple device (CCD) or complementary metal oxide semiconductor (CMOS)), (b) illuminant (D-65, fluorescent lamps, among others), (c) the background (with high contrast for the object of interest), (d) trigger device (used to start image acquisition), and (e) a frame grabber (to capture the actual image). The capture procedure can be divided into the following steps: the illuminator irradiates the object, the image sensor receives the light reflected from the object and the background, and when the trigger is activated, the system extracts the color characteristics and converts them to electrical signals and then the grabber frame stores the image taken [22, 23]. Once the image is on the computer or other processing device, image processing algorithms are used to analyze the data. The basic steps can be listed as: (a) segmentation of images (the background is 
separated from the region of interest), (b) extraction of characteristics (select pixels of interest); for this stage, several functions and algorithms have been developed in order to get an adequate image processing of the scene. Next, we analyze the data generated from the previous process, the system extracts the color attribute of the objects in the image using colorimetric techniques, as well as others as morphological and texture parameters [24-26], and finally the analysis results are presented.

Colorimetry is the scientific area that measures, quantifies, and represents color [27]. It is very useful in different areas because it provides the ability to turn color into an objective factor rather than a subjective one. Complementing this scientific area with the technology of computer vision systems, it is possible to see the color characteristics in a digital and standard way, in addition to performing the color evaluation with a noninvasive and noncontact procedure, which makes it a suitable technology for application in agriculture and the food industry for quality assessment. Due to their versatility, many other production systems can benefit from the features offered by artificial vision systems, image processing, and colorimetry.

The aim of this study is to evaluate noninvasive and noncontact techniques of image processing and color analysis; for example, the estimation of color from postharvest Habanero chili at different maturity stages is shown. Moreover, the capability of color assessment as a region, instead of a punctual area as is done with a typical colorimeter, identifies threshold values in these stages.

The goal is to identify and quantify color attributes of Habanero chili fruits using the following stages:

- Image acquisition system (setup).

- Image processing (threshold technique and algorithms).

- Feature extraction (pixels of interest and color calculations).

- Color analysis (attribute identification, quantification and classification).

\section{Image processing}

The techniques of image processing are related to algorithms that manipulate the numerical representation of the images to obtain useful information [28]. In particular, segmentation subdivides the digital image into multiple regions or objects that have common characteristics [29]. This action involves several steps that must be taken, before the images can provide valuable data. First, region of interest (ROI) must be identified, i.e., regions in the image that have pixels that matter to the application and which must be separated from the background. In order to develop algorithms that perform this work, it is necessary to define whether the image is black and white or colored, and then a criterion must be established for the segmentation, which must focus on morphological, texture, or colorimetric parameters, before establishing any flow chart as solution. It should be mentioned that algorithms may 
be suitable for many applications, but none of them is generally applicable to all images, and therefore, suitable algorithms for each particular application should be used [30, 31].

\subsection{Image acquisition system and color image representation}

It is essential to use an image acquisition system that suits the application properly. It must be defined what type of objects or products will be placed in the system, as well as set the scene location and choose the appropriate settings to obtain acceptable images. The issue of lighting (natural or artificial) depends on the scenes required by the application. Once the capture conditions are adequate, a vision sensor (CCD or CMOS) must be selected, which will suit the entire system for proper performance. A digital camera receives light variations corresponding to images onto a CCD device. The CCD contains capacitors that are stimulated by visible radiation and three filters adjusted for three basic colors: red (R), green $(G)$, and blue (B). Theoretically, every color can be reproduced by the combination of three primary colors.

A color image are represented as a $\mathrm{M} \times \mathrm{N} \times 3$ (components) array of color pixels, where each color pixel is a triplet corresponding to the RGB components of and image at specific spatial location, as shown in Figure 1. By convention, the three images formed and RGB color image are referred to as the $R, G, B$ component images. The data class of the component from the image determines their ranges of values, for example [0-255] or [0-65,535] for RGB images of class uint8 or uint16, respectively [32]. The RGB color space is an additive color model that uses transmitted light to display colors. It is used for television and other devices screens; so this model is device dependent (Its appearance depends on the display.)

A summary of machine vision systems, image processing, and color analysis frequently implemented in the agriculture is presented in Table 1. First column corresponds to the type of application, and four general and typical areas are included. The type of tasks performed by these applications is shown in the second column, including the corresponding references. Third column shows the type of setup employed for each application, and the last column shows the locations where these systems are typically deployed.

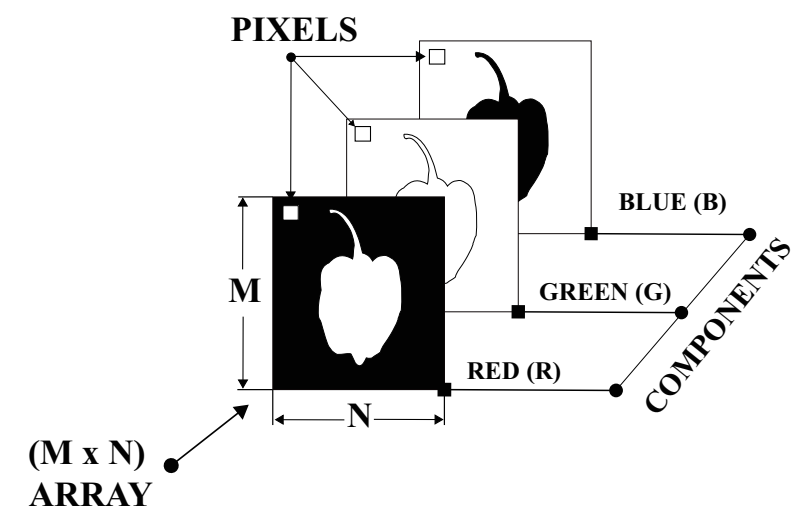

Figure 1. Color representation of digital image and their RGB components. 


\begin{tabular}{|c|c|c|c|}
\hline Application & Task & Type of setup & Location \\
\hline In situ & $\begin{array}{l}\text { Monitoring } \\
\text { Color } \\
\text { Diseases } \\
\text { Plague } \\
\text { Growth } \\
\text { Behavior } \\
\text { [33-36] }\end{array}$ & $\begin{array}{l}\text { Portail } \\
\text { By satellite } \\
\text { Aerial inspection [37-42] }\end{array}$ & On field \\
\hline Harvesting robots & $\begin{array}{l}\text { Harvest } \\
\text { Shape } \\
\text { Color } \\
\text { [43-46] }\end{array}$ & Mobile robot & On field \\
\hline Online sorting & $\begin{array}{l}\text { Sorting } \\
\text { Color } \\
\text { Size } \\
\text { Quality } \\
\text { Blemish } \\
\text { [47-49] }\end{array}$ & $\begin{array}{l}\text { Static machine (placed on a } \\
\text { production line) }\end{array}$ & Packer station \\
\hline Postharvest & $\begin{array}{l}\text { Analysis } \\
\text { Quality } \\
\text { Shelf life } \\
\text { Volume } \\
\text { Blemish } \\
{[8,50-54]}\end{array}$ & Desktop & Laboratory \\
\hline
\end{tabular}

Table 1. Image acquisition setups and their typical usage.

\subsection{Color image segmentation}

Algorithms for color image segmentation based on the technique of threshold segmentation should be executed in triplicate, due to the structure of the color image [55, 56]. A typical segmentation process fills in with ones and zeros of the image matrix locations, corresponding to the selected regions in each of the color channels of an image, as shown in Figure 2.

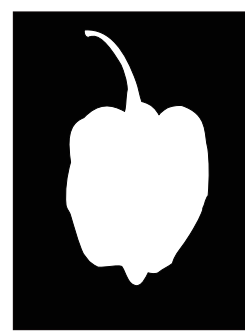

a)

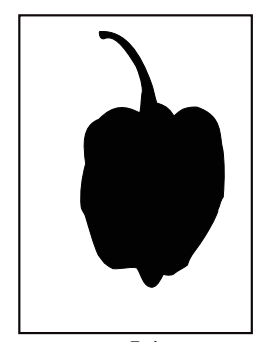

b)

Figure 2. Segmented image: (a) background filled with zeros and (b) background filled with ones.

\section{Color calculations}

The Commission Internationale de l'Eclairage (CIE) determines regulations, standards, and recommendations for color measurements. The CIELAB color space is an international standard 
developed by the CIE in 1976. Within CIELAB, a psychometric index of lightness ( $\left.\mathrm{L}^{*}\right)$ and two color coordinates $\left(a^{*}\right.$ and $\left.b^{*}\right)$ are defined. $L^{*}$ is a qualitative attribute of relative luminosity, which is the property according to which each color can be considered as equivalent to a member of the gray scale, ranging between black $\left(L^{*}=0\right)$ and white $\left(L^{*}=100\right)$. Negative values from $a^{*}$ correspond to greenish and the positives to the reddish ones, whereas the yellowish colors takes negatives values from $b^{*}$ and the positive for bluish ones [57].

It is well known in the food industry that the CIELAB color space is used to analyze color changes in a qualitative way [58-62]. Color and appearance are closely related to the sensory properties and chemical composition of food. Color is usually measured by tristimulus colorimetry. The color stimulus is composed of three different parameters, giving the color a three-dimensional nature.

The color attributes are described in CIELAB as:

- Lightness: This feature indicates if a color is lighter or darker. It is a relative measure of the reflected light against the absorbed. Value 0 corresponds to black and value 100 is assigned to white.

- Chroma: It determines for each hue, the color difference taking as reference the gray level with same lightness. It can take positive values from zero.

- Hue: It is the main attribute. It is a qualitative property, which allows classifying colors as red, yellow, etc. It is related to differences in absorbance of radiant energy at different wavelengths. Hue is specified as an angle.

These attributes are often expressed as $\mathrm{L}^{*}, \mathrm{C}_{\mathrm{ab}}{ }^{*}$, and $\mathrm{h}_{\mathrm{ab}}{ }^{\circ}$, respectively; according to the CIELAB color space, it can be represented as Cartesian coordinates of polar coordinates $\mathrm{C}_{\mathrm{ab}}{ }^{*}$ and $\mathrm{h}_{\mathrm{ab}}{ }^{\circ}$. It can be used on a variety of instruments, such as colorimeters, spectrophotometers, and spectroradiometers. However, these instruments require homogenous samples to achieve a uniform color, which becomes a tedious and complicated task to measure the color of heterogeneous or small objects, such as grape berries and grape seeds. In these cases, the use of digital images for the extraction of color characteristics is advantageous. Digital image analysis appears as a suitable complement since it is possible to extract not only color characteristics but also other characteristics such as shape, texture, and homogeneity.

On the other hand, due to the nature of the CIELAB color space, the calculation of the Euclidean distance can be applied between neighboring samples, in order to obtain a relation between a quantitative and qualitative value on the variation of the color appearance of an object.

\section{Application of image processing and color analysis of Habanero chili pepper}

Since consumers buy with their eyes, color is considered one of the most important quality parameters of food products. Normally, this is determined by human inspection, or measured using a colorimeter or a spectrophotometer. The first process is subjective and susceptible 
to fatigue. The second is limited to measure just a small area of the food product, making it difficult to obtain a clear view of the color of the complete sample [63]. In order to overcome these limitations, a system of artificial vision, image processing, and color analysis has been applied to measure the postharvest color of the Habanero chili (Capsicum chinense Jacq.) at different stages of ripening.

\subsection{Genus capsicum}

The Habanero chili belongs to the family Solanaceae and genus Capsicum. This genus consists of 27 species, five of which have been domesticated and are used worldwide as vegetables, spices, and condiments: Capsicum annum L., Capsicum frutescens L., Capsicum chinense J., Capsicum pubescens $R$. $\mathcal{E}$ P., and Capsicum baccatum L., where nonpungent cultivars of C. annum are the most consumed and are the main objective of most breeding programs [64].

Chili peppers (Capsicum spp.) are well known for their ability to cause an intense organoleptic sensation of heat when consumed (pungency). Capsaicin and its analogues, collectively called capsaicinoids (a group of alkaloids), are responsible for giving pungency or heat to the fruit; the pungent feature of peppers is only present in the members of the genus Capsicum [65-67].

The Capsicum chinense Jacq. is a very aromatic pepper and also is one of the hottest peppers in the world [68]. These fruits are commonly used to give a pungent or hot sensation to many different meals and food products all around the world. During the past decade, it has been reported that the consumption of certain foods and spices such as pepper may have a positive effect on health. Genus Capsicum shows an incredible diversity and is consumed by a large section of population throughout the world because of its impressive health beneficial chemical compounds such as capsaicinoids, carotenoids (provitamin A), flavonoids, vitamins (vitamins $\mathrm{C}$ and E), minerals, essential oils, and aroma of the fruits. These compounds have been shown to possess anticancer, anti-inflammatory, antimicrobial, and antioxidant properties [69]. They are important from the economic point of view for countries like Mexico, not only for the preparation of regional foods that have made Mexican gastronomy famous all over the world, but also because of the great amount and genetic variability that occurs in its territory, especially spicy species [68, 70-73].

\subsection{Methodology}

The methodology used is described as follows: (1) specimens of Habanero chili here collected and arranged in three groups depending on their maturity stage by visual inspection. (2) The samples are moved to the laboratory to be placed in the machine vision system and the acquisition process is setup. (3) The acquisition process starts with a 24 sampling rates and finishes after 15 days, capturing a single image from each specimen. (4) Once the images were acquired, a database with a total of 900 images was generated. (5) The algorithms of image processing and color analysis were applied to this dataset. 6) Finally, the algorithms generate results with color segmentation, colorimetric measurements in CIELAB color space, color analysis, and statistical analysis of the dataset. 


\subsubsection{Samples}

For this case of study samples of Habanero chili were harvested from an aquaponic greenhouse culture. The selection of the samples was carried out by a specialized technician. The expert harvested a representative group of Habanero chili, which showed different stages of maturity. A color categorization was performed by visual inspection. The samples were separated into three groups of colors (green, yellowish and orange), with 20 specimens per group.

\subsubsection{Setup of machine vision system}

The artificial vision system used a color CCD camera as image capture device. The lighting system contained fluorescent lamps mounted on top to avoid shadows. In order to control the camera and to download the images, we used a standard PC with MATLAB. The system design allowed the camera to move the samples above to keep them stable. Because of the protrusions and cavities presented by the Habanero chili, it is difficult to keep the surface of interest in exactly the same position along the experiment. As shown in Figure 3, the samples were placed in the confined space of the machine vision system to acquire the corresponding images.

\subsubsection{Image processing algorithms}

To accomplish the image processing tasks, the flow chart was followed as showed in Figure 4 . The algorithms are executed using suitable functions in order to get reliable information from digital images. At the beginning, the image from sample is captured using the image acquisition system. Then, image processing routines carry out the required operations to separate the ROI, as well as to convert the image from RGB color space to CIELAB. The calculations to obtain the CIELAB components ( $\mathrm{L}^{*}, \mathrm{a}^{*}, \mathrm{~b}^{*}$, Chroma, Hue angle) using tristimulus colorimetry are performed to generate the corresponding array. Finally, the color analysis from the Habanero chili in postharvest conditions can be accomplished.

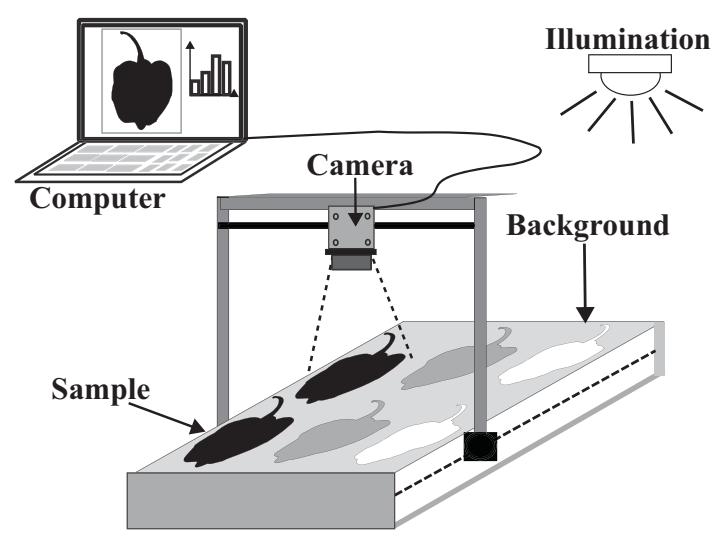

Figure 3. Proposed setup for the case of study. 


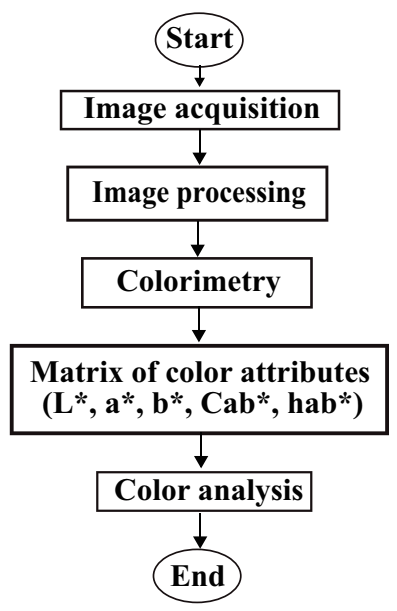

Figure 4. Flow chart used for the image processing algorithm.

The original and processed images, by the algorithms from the dataset, are shown in Figure 5. One image, aleatory selected, from each categorized group (green, yellowish, and orange) is presented. At the top, you can identify the categorization of groups, and below is the corresponding label of the sample. Then, the original images, just as the vision system acquired them, are presented. In the middle, the label that indicates the exact day of the acquisition is located. At the bottom, the processed images are shown, where you can clearly observe the segmentation process and how the algorithms filled the background with zeros, and only the information from the region of interest is processed (ROI).

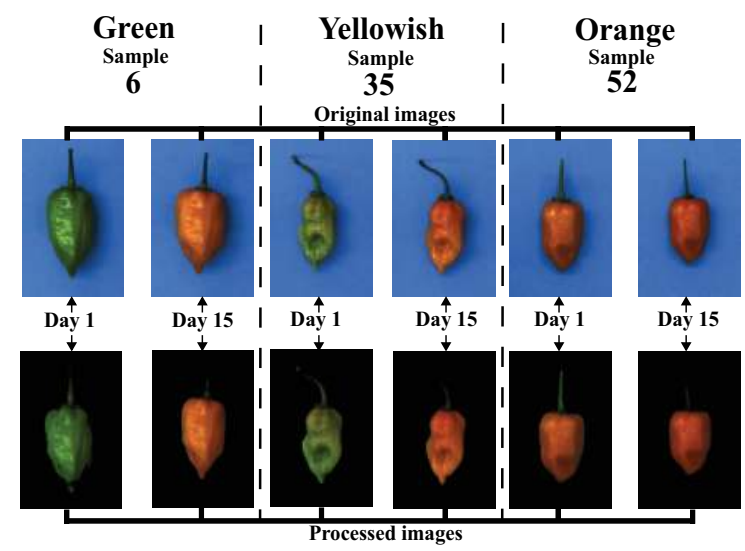

Figure 5. Original and processed images of Habanero chili. 


\subsubsection{Color and statistical analysis}

Habanero chili is a climacteric fruit, which means that once it is cut, it begins to ripen. Depending on the variety of Capsicum chinense Jacq., the color of the Habanero chili changes during maturation. In general, changes occur from the dark green, in its initial stages, and then go through the yellowish-green until reaching an orange color, in the final stage of maturity.

Color evolution can be represented as hue angles $\left(\mathrm{h}_{\mathrm{ab}}{ }^{\circ}\right)$ in a polar graph. Typically, Habanero chili initiates maturity with green stage (under the threshold of $h_{a b}=120^{\circ}$ for green) and then it moves through the yellowish stage (between the threshold $h_{a b}=120$ and $60^{\circ}$ for yellowish) to achieve orange colors (crossing the threshold of $h_{a b}=60^{\circ}$ for orange) in the final stage of maturity, as time passes. The color information from the dataset showed this behavior, and the statistical analysis presented in Figure 6 demonstrates that image processing and colorimetry are capable of extracting reliable values from acquired images and detect color changes from these agriculture products. Therefore, this methodology described, as noncontact technique, can be considered a suitable option to analyze the color of Habanero chili.

In Figure 6, chart (a) shows the variation from the green group. In average values of hue angle, a high color change is presented, due to the gradual transition from green colors to oranges passing through the yellowish ones during their maturity process. In chart (b), a descendant gradual color change can be appreciated, even when crossing the threshold of

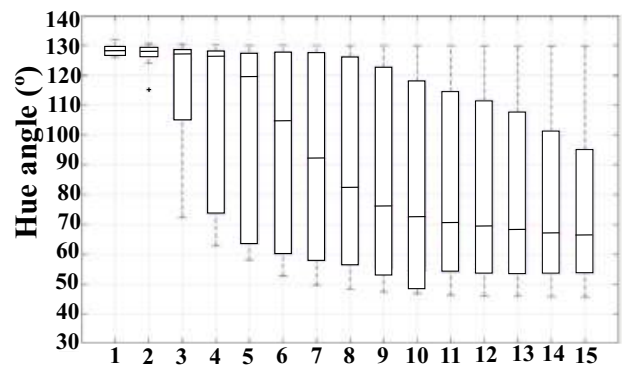

a)

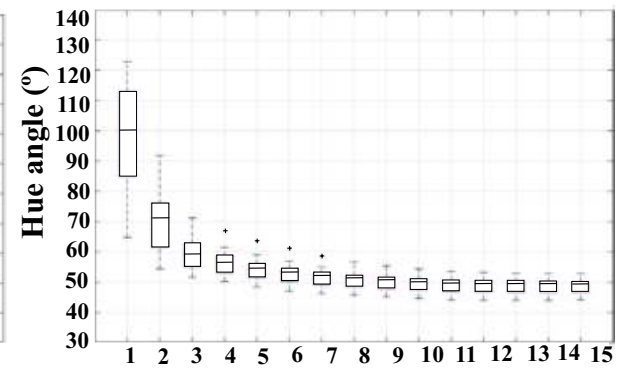

b)
Days

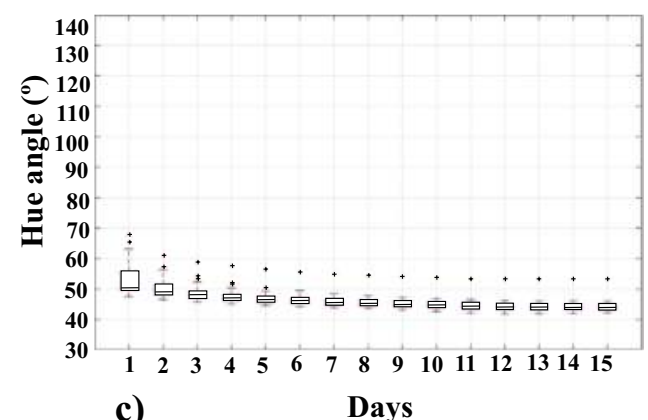

Figure 6. Box and whiskers chart from each group: (a) green, (b) yellowish, and (c) orange. 


\begin{tabular}{lllll}
\hline Source & SS & DF & MS & $F^{>} \mathbf{F}_{0.05}$ \\
\hline Green & & & & \\
Days & 91722.7 & 14 & 6551.62 & $-17>>1.692$ \\
Error & 228586.7 & 285 & 802.06 & - \\
Total & 320309.4 & 299 & - & $100.21>>1.692$ \\
Yellowish & & & 3518.91 & - \\
Days & 49264.8 & 14 & 35.12 & - \\
Error & 10008.2 & 285 & - & $14.6>>1.692$ \\
Total & 59,273 & 299 & & - \\
Orange & & 14 & 9.369 & - \\
Days & 1915.77 & 285 & - & \\
Error & 2670.3 & 299 & & \\
Total & 4586.07 & &
\end{tabular}

Table 2. One-way ANOVA table for each group.

$h_{a b}=60^{\circ}$. Instead, the third group (c), corresponding to the orange ones, remains after the threshold of $h_{\mathrm{ab}}=60^{\circ}$ with a slow progressive color changes.

A one-way ANOVA was conducted to evaluate the relationship between color changes in 20 Habanero chili and 15 days of sampling. Table 2 displays the summary for the one-way ANOVA for each group of samples. With the null hypothesis $\left(\mathrm{H}_{0}\right)$, it was showed that all the color values are equal during 15 days. In the analysis, it was shown that in green, yellowish, and the orange groups, the ANOVA was significant: $\mathrm{F}(14,285)=8.17, \mathrm{~F}(0.05)=1.692, \mathrm{~F}(14$, $285)=100.21, \mathrm{~F}(0.05)=1.692$, and $\mathrm{F}(14,285)=8.17, \mathrm{~F}(0.05)=1.692$, respectively. The ANOVA results allowed to reject the null hypothesis and supported the conclusion that there is a statistically significant color change during days for the green, yellowish, and orange groups.

\section{Conclusions}

Artificial vision systems combined with image processing and color analysis are a reliable and affordable option when specific applications require the use of noninvasive and noncontact techniques. Similar characteristics of the samples are extracted from their images and grouped for further analysis using image processing techniques, which helps to obtain consistent and reliable separations of elements. The CIELAB color space provides the parameters needed to analyze and calculate important characteristics of a color image. Color differences can be detected more directly using the CIELAB color space, and it is important to mention that a color difference magnitude can be imperceptible to the naked eye, but it is a basic operation for the vision systems. However, the context in the color analysis should be considered as an important factor, for the proper interpretation of the data generated from the previous process. For example, the color attribute of the Habanero chili is a fundamental parameter 
for the appearance of the genus capsicum, which can be evaluated by image processing and colorimetry to detect color changes with adequate and reliable results in postharvest analysis. Trend in applications of color analysis and image processing for agriculture will continue to increase in the near future, due to the great variety of colors and shapes of the products, in particular, the interest to obtain the best quality.

\section{Acknowledgements}

The authors wish to thank the National Council for Science and Technology (CONACyT) for providing the funding to carry out this research, as well as to the people involved in this research at the State University of Sonora, the Autonomous University of Baja California, Program for Strengthening Educational Quality (PFCE) and the Center for Scientific Research and Higher Education at Ensenada.

\section{Author details}

Jesús Raúl Martínez Sandoval ${ }^{1 *}$, Miguel Enrique Martínez Rosas², Ernesto Martínez Sandoval², Manuel Moisés Miranda Velasco ${ }^{2}$ and Humberto Cervantes De Ávilaª

*Address all correspondence to: jesus.martinez@ues.mx

1 State University of Sonora, Hermosillo, Mexico

2 Autonomous University of Baja California, Ensenada, Mexico

\section{References}

[1] Zhang B, Huang W, Li J, Zhao C, Fan S, Wu J, Liu C. Principles, developments and applications of computer vision for external quality inspection of fruits and vegetables: A review. Food Research International. 2014. DOI: 10.1016/j.foodres.2014.03.012

[2] Ayman HAE, Ayman AAK. Understanding color image processing by machine vision for biological materials. In: Structure and function of food engineering. INTEHC; 2012. pp. 227-274. DOI: $10.5772 / 50796$

[3] Feng Y-Z, Sun D-W. Application of Hyperspectral imaging in food safety inspection and control: A review. Critical Reviews in Food Science and Nutrition. 2012;52(11):1039-1058. DOI: $10.1080 / 10408398.2011 .651542$

[4] Saldaña E, Siche R, Luján M, Quevedo R. Review: Computer vision applied to the inspection and quality control of fruits and vegetables. Revisão: visão computacional aplicada à inspeção e ao controle da qualidade de frutas e verduras. Brazilian Journal of Food Technology, Campinas. 2013;16(4):254-272. DOI: 10.1590/S1981-67232013005000031 
[5] Pathare PB, Opara UL, Al-Said FAJ. Colour measurement and analysis in fresh and processed foods: A review. Food and Bioprocess Technology. 2013;6(1):36-60. DOI: 10.1007/ s11947-012-0867-9

[6] Maldonado A, Vigneault C, Nakaji K. Postharvest Technologies of Fresh Horticulture Produce. In: Horticulture, 2012, pp. 164-172, InTech, ISBN: 9789535102526

[7] G Hareesh K S SL,NV. Quality inspection and grading of agricultural and food products by computer vision-a review. International Journal of Computer Applications. 2010;2(1):975-8887. DOI: 10.5120/612-863

[8] Wabali VC, Esiri A, Zitte L. A sensory assessment of color and textural quality of refrigerated tomatoes preserved with different concentrations of potassium permanganate. Food Science and Nutrition. 2017;5(3):434-438. DOI: 10.1002/fsn3.410

[9] Ji B, Wang J, Liu W. Color-based automatic quality control for roasting chicken. Computers and Electronics in Agriculture. 2016;123:49-56. DOI: 10.1016/j.compag.2016.01.028

[10] Singh H, Gill N. Machine vision based color grading of Kinnow mandarin. International Journal of Advanced Research in Computer Science and Software Engineering. 2015; 5(5):1253-1259

[11] Schmilovitch Z, Ignat T, Alchanatis V, Gatker J, Ostrovsky V, Felföldi J. Hyperspectral imaging of intact bell peppers. Biosystems Engineering. 2014;117(C):83-93. DOI: 10.1016/ j.biosystemseng.2013.07.003

[12] Krig S. Computer vision metrics: Survey, taxonomy, and analysis. Computer Vision Metrics:Survey, Taxonomy, and Analysis. 2014;9781430259:1-472. DOI:10.1007/978-1-43025930-5

[13] Morene OC., Gila DMM, Puerto DA, García JG, Ortega JG. Automatic determination of peroxides and acidity of olive oil using machine vision in olive fruits before milling process. IST 2015-2015 IEEE International Conference on Imaging Systems and Techniques, Proceedings; 2015. DOI: 10.1109/IST.2015.7294543

[14] Rahman MO, Hussain A, Scavino E, Basri H, Hannan M a. Intelligent computer vision system for segregating recyclable waste papers. Expert Systems with Applications. 2011;38(8):10398-10407. DOI: 10.1016/j.eswa.2011.02.112

[15] Kang, S. P., East AR, Trujillo FJ. Colour vision system evaluation of bicolour fruit: A case study with "B74" mango. Postharvest Biology and Technology. 2008;49(1):77-85. DOI: 10.1016/j.postharvbio.2007.12.011

[16] Barrett DM, Beaulieu JC, Shewfelt R. Color, flavor, texture, and nutritional quality of fresh-cut fruits and vegetables: Desirable levels, instrumental and sensory measurement, and the effects of processing. Critical Reviews in Food Science and Nutrition. 2010;50(5):369-389. DOI: 10.1080/10408391003626322

[17] Chauhan APS, Singh AP. Intelligent estimator for assessing apple fruit quality. International Journal of Computer Applications. 2012;60(5):35-41 
[18] Zareiforoush H, Minaei S, Alizadeh MR, Banakar A. Qualitative classification of milled rice grains using computer vision and metaheuristic techniques. Journal of Food Science and Technology. 2016;53(1):118-131. DOI: 10.1007/s13197-015-1947-4

[19] González IA, Osorio C, Meléndez-Martínez AJ, González-Miret ML, Heredia FJ. Application of tristimulus colorimetry to evaluate colour changes during the ripening of Colombian guava (Psidium Guajava L.) varieties with different carotenoid pattern. International Journal of Food Science \& Technology. 2011;46(4):840-848. DOI: 10.1111/ j.1365-2621.2011.02569.x

[20] Heredia FJ, González-Miret ML, Meléndez-Martínez AJ, Vicario IM. Instrumental assessment of the sensory quality of juices. In: Instrumental assessment of food sensory quality. 2013. pp. 565-610, Woodhead Publishing, ISBN: 9780857094391

[21] Meléndez-Martínez AJ, Gómez-Robledo L, Melgosa M, Vicario IM, Heredia FJ (2011). Color of orange juices in relation to their carotenoid contents as assessed from different spectroscopic data. Journal of Food Composition and Analysis, 24(6):837-844. DOI: 10.1016/j.jfca.2011.05.001

[22] Rodríguez-Pulido FJ, Gordillo B, Lourdes González-Miret M, Heredia FJ. Analysis of food appearance properties by computer vision applying ellipsoids to colour data. Computers and Electronics in Agriculture. 2013;99:108-115. DOI: 10.1016/j.compag.2013.08.027

[23] Rodríguez-Pulido FJ, Gómez-Robledo L, Melgosa M, Gordillo B, González-Miret ML, Heredia FJ. Ripeness estimation of grape berries and seeds by image analysis. Computers and Electronics in Agriculture. 2012;82:128-133. DOI: 10.1016/j.compag.2012.01.004

[24] Lu R, Cen H. Non-destructive methods for food texture assessment. In: Instrumental assessment of food sensory quality; 2013. p. 230-255e. DOI: 10.1533/9780857098856.2.230

[25] Lu R. Principles of solid food texture analysis. In: Instrumental assessment of food sensory quality. 2013. p. 103-128. DOI: 10.1533/9780857098856.1.103

[26] Kim DG, Burks TF, Qin J, Bulanon DM. Classification of grapefruit peel diseases using color texture feature analysis. Int J Agric \& Biol Eng Open Access at Http://www.ijabe. org. International journal of agricultural and biological engineering. 2009;2(23):41-50. DOI: 10.3965/j.issn.1934-6344.2009.03.041-050

[27] Collewet C, Marchand E. Colorimetry-based visual servoing. 2009 IEEE/RSJ International Conference on Intelligent Robots and Systems. IEEE; 2009. DOI: 10.1109/IROS. 2009.5354416

[28] Wang XY, Sun WW, Wu ZF, Yang HY, Wang QY. Color image segmentation using PDTDFB domain hidden Markov tree model. Applied Soft Computing Journal. 2015;29:138-152. DOI: 10.1016/j.asoc.2014.12.023

[29] Bova N, Ibanez O, Cordon O. Image Segmentation Using Extended Topological Active Nets Optimized by Scatter Search. IEEE Computational Intelligence Magazine. 2013; 8(1):16-32. DOI: 10.1109/MCI.2012.2228587 
[30] Peng B, Li T. A probabilistic measure for quantitative evaluation of image segmentation. IEEE Signal Processing Letters. 2013;20(7):689-692. DOI: 10.1109/LSP.2013.2262938

[31] Russ JC. The Image Processing Handbook. Image Processing (Sixth Edit): CRC Press; 2011. DOI: $10.1201 / 9781420040760$

[32] Gonzalez RC, Woods RRE, Eddins SL. Digital Image Processing Using Matlab. Gatesmark Publishing: Gatesmark Publishing; 2004

[33] Mehta SS, Ton C, Asundi S, Burks TF. Multiple camera fruit localization using a parti cle filter. Computers and Electronics in Agriculture. 2017;142:139-154. DOI: 10.1016/j.com pag.2017.08.007

[34] Pires RDL, Gonçalves DN, Oruê JPM, Kanashiro WES, Rodrigues JF, Machado BB, Gonçalves WN. Local descriptors for soybean disease recognition. Computers and Electronics in Agriculture. 2016;125:48-55. DOI: 10.1016/j.compag.2016.04.032

[35] Li Y, Cao Z, Lu H, Xiao Y, Zhu Y, Cremers AB. In-field cotton detection via region-based semantic image segmentation. Computers and Electronics in Agriculture. 2016;127:475-486. DOI: 10.1016/j.compag.2016.07.006

[36] Çakir Y, Kirci M, Güneş EO, Üstündağ, BB. Detection of oranges in outdoor conditions. In: 2013 2nd International Conference on Agro-Geoinformatics: Information for Sustainable Agriculture, Agro-Geoinformatics 2013. 2013. p. 500-503. DOI: 10.1109/ Argo-Geoinformatics.2013.6621971

[37] ZHOU, Qing bo, YU, Qiang yi, LIU, Jia, WU, Wen bin, TANG, Hua jun. Perspective of Chinese GF-1 high-resolution satellite data in agricultural remote sensing monitoring. Journal of Integrative Agriculture. 2017;16(2):242-251, DOI: 10.1016/ S2095-3119(16)61479-X.

[38] Pasher J, McGovern M, Putinski V. Measuring and monitoring linear woody features in agricultural landscapes through earth observation data as an indicator of habitat availability. International Journal of Applied Earth Observation and Geoinformation. 2016;44:113-123. DOI: 10.1016/j.jag.2015.07.008.

[39] Liu K, Zhou Q, Wu W, Xia T, Tang H. Estimating the crop leaf area index using hyperspectral remote sensing. Journal of Integrative Agriculture. 2016;15(2):475-491. DOI: 10.1016/S2095-3119(15)61073-5

[40] Elarab M, Ticlavilca AM, Torres-Rua AF, Maslova I, McKee M. Estimating chlorophyll with thermal and broadband multispectral high resolution imagery from an unmanned aerial system using relevance vector machines for precision agriculture. International Journal of Applied Earth Observation and Geoinformation. 2015;43:32-42. DOI: 10.1016/j. jag.2015.03.017

[41] Rokhmana CA. The potential of UAV-based remote sensing for supporting precision agriculture in Indonesia. Procedia Environmental Sciences. 2015;24:245-253. DOI: 10.1016/j. proenv.2015.03.032 
[42] Murillo-Bracamontes EA, Martinez-Rosas ME, Miranda-Velasco MM, Martinez-Reyes HL, Martinez-Sandoval JR, Cervantes-De-Avila H. Implementation of Hough transform for fruit image segmentation. Procedia Engineering. 2012;35:230-239. DOI: 10.1016/j. proeng.2012.04.185

[43] Wang C, Tang Y, Zou X, SiTu W, Feng W. A robust fruit image segmentation algorithm against varying illumination for vision system of fruit harvesting robot. Optik. 2017;131:626-631. DOI: 10.1016/j.ijleo.2016.11.177

[44] Mehta SS, Burks TF. Multi-camera Fruit Localization in Robotic Harvesting. IFACPapersOnLine. 2016;49(16):90-95. DOI: 10.1016/j.ifacol.2016.10.017

[45] García-Luna F, Morales-Díaz A. Towards an artificial vision-robotic system for tomato identification. IFAC-PapersOnLine. 2016;49(16):365-370. DOI: 10.1016/j.ifacol.2016.10.067

[46] Zujevs A, Osadcuks V, Ahrendt P. Trends in robotic sensor Technologies for Fruit Harvesting: 2010-2015. Procedia Computer Science. 2015;77:227-233. DOI: 10.1016/j. procs.2015.12.378

[47] Mo C, Kim G, Kim MS, Lim J, Lee K, Lee WH, Cho BK. On-line fresh-cut lettuce quality measurement system using hyperspectral imaging. Biosystems Engineering. 2017;156:38-50. DOI: 10.1016/j.biosystemseng.2017.01.005

[48] Jhawar J. Orange Sorting by Applying Pattern Recognition on Colour Image. Physics Procedia. December 2016;78(2015):691-697. DOI: 10.1016/j.procs.2016.02.118

[49] Kim MS. Online screening of fruits and vegetables using hyperspectral line-scan imaging techniques. In: High Throughput Screening for Food Safety Assessment. 2014, pp. 467-490. Woodhead Publishing, ISBN: 9780857098078.

[50] Hashimoto A, Muramatsu T, Suehara K, Kameoka S, Kameoka T. Color evaluation of images acquired using open platform camera and mini-spectrometer under natural lighting conditions. Food Packaging and Shelf Life. 2017. DOI: 10.1016/j.fpsl.2017.08.008

[51] Cho JS, Lee HJ, Park JH, Sung JH, Choi JY, Moon KD. Image analysis to evaluate the browning degree of banana (Musa spp.) peel. Food Chemistry. 2016;194:1028-1033. DOI: 10.1016/j.foodchem.2015.08.103

[52] Bac CW, Hemming J, Van Henten EJ. Pixel classification and post-processing of plant parts using multi-spectral images of sweet-pepper. IFAC Proceedings Volumes. 2013;46(4):150-155. DOI: 10.3182/20130327-3-JP-3017.00035.

[53] Ataş M, Yardimci Y, Temizel A. A new approach to aflatoxin detection in chili pepper by machine vision. Computers and Electronics in Agriculture. 2012;87:129-141. DOI: 10.1016/j.compag.2012.06.001

[54] Omid M, Khojastehnazhand M, Tabatabaeefar A. Estimating volume and mass of citrus fruits by image processing technique. Journal of Food Engineering. 2010;100(2):315-321. DOI: 10.1016/j.jfoodeng.2010.04.015 
[55] Vitzrabin E, Edan Y. Adaptive thresholding with fusion using a RGBD sensor for red sweet-pepper detection. Biosystems Engineering. 2016;146:45-56. DOI: 10.1016/j.biosyst emseng.2015.12.002

[56] Zhang H, Fritts JE, Goldman S a. Image segmentation evaluation: A survey of unsupervised methods. Computer Vision and Image Understanding. 2008;110(2):260-280. DOI: 10.1016/j.cviu.2007.08.003

[57] COMMISSION INTERNATIONALE DE L'ECLAIRAGE. (2004). CIE Technical Report Colorimetry 15:2004 3rd Edition.

[58] Zheng H, Lu H. A least-squares support vector machine (LS-SVM) based on fractal analysis and CIELab parameters for the detection of browning degree on mango (Mangifera Indica L.). Computers and Electronics in Agriculture. 2012;83:47-51. DOI: 10.1016/j. compag.2012.01.012

[59] García-Marino M, Escudero-Gilete ML, Heredia FJ, Escribano-Bailón MT, RivasGonzalo JC. Color-copigmentation study by tristimulus colorimetry (CIELAB) in red wines obtained from Tempranillo and Graciano varieties. Food Research International. 2013;51(1):123-131. DOI: 10.1016/j.foodres.2012.11.035

[60] Liang Z, Sang M, Fan P, Wu B, Wang L, Yang S, Li S. CIELAB coordinates in response to berry skin anthocyanins and their composition in Vitis. Journal of Food Science. 2011;76(3):C490-C497. DOI: 10.1111/j.1750-3841.2011.02095.x

[61] Gallez L, Marconi A, Tourn E, González-miret M.L., Heredia F.J. Colour of Honeys from the SouthWestern Pampas Region: Relationship between the Pfund Color Scale and CIELAB Coordinates, In: Color in Food. Technological and Psychophysical Aspects. 2012, pp. 133-141, CRC Press Inc. ISBN: 978-1-4398-7693-0.

[62] Esparza I, Santamaría C, Calvo I, Fernández JM. Significance of CIELAB parameters in the routine analysis of red wines Relevancia de los parámetros CIELAB en el análisis de rutina de vinos tintos. CyTA - Journal of Food. 2009;7(3):189-199. DOI: 10.1080/ 19476330903068001

[63] van Roy J, Keresztes JC, Wouters N, De Ketelaere B, Saeys W. Measuring colour of vine tomatoes using hyperspectral imaging. Postharvest Biology and Technology. 2017;129: 79-89. DOI: 10.1016/j.postharvbio.2017.03.006

[64] Ibiza VP, Cañizares J, Nuez F. EcoTILLING in capsicum species: Searching for new virus resistances. BMC Genomics. 2010;11(1):631. DOI: 10.1186/1471-2164-11-631

[65] Sarpras M, Gaur R, Sharma V, Chhapekar SS, Das J, Kumar A, et al. Comparative analysis of fruit metabolites and pungency candidate genes expression between Bhut jolokia and other capsicum species. PLoS One. 2016;11(12):1-19. DOI: 10.1371/journal. pone.0167791

[66] Ryu WK, Kim HW, Kim GD, Rhee HI. Rapid determination of capsaicinoids by colorimetric method. Journal of Food and Drug Analysis. 2016:2-7. DOI: 10.1016/j.jfda.2016.11.007 
[67] Stewart C, Mazourek M, Stellari GM, O'Connell M, Jahn M. Genetic control of pungency in C. Chinense via the Pun1 locus. Journal of Experimental Botany. 2007;58(5):979-991. DOI: $10.1093 / \mathrm{jxb} / \mathrm{erl} 243$

[68] Das S, Teja KC, Duary B, Agrawal PK, Bhattacharya SS. Impact of nutrient management, soil type and location on the accumulation of capsaicin in Capsicum Chinense (Jacq.): One of the hottest chili in the world. Scientia Horticulturae. 2016;213:354-366. DOI: 10.1016/j.scienta.2016.10.041

[69] Duelund L, Mouritsen OG. Contents of capsaicinoids in chillies grown in Denmark. Food Chemistry. 2017;221:913-918. DOI: 10.1016/j.foodchem.2016.11.074

[70] Cisneros-PinedaO,Torres-TapiaLW,Gutiérrez-PachecoLC,Contreras-MartínF,GonzálezEstrada T, Peraza-Sánchez SR. Capsaicinoids quantification in chili peppers cultivated in the state of Yucatan, Mexico. Food Chemistry. 2007;104(4):1755-1760. DOI: 10.1016/j. foodchem.2006.10.076

[71] Powis TG, Murrieta EG, Lesure R, Bravo RL, Grivetti L, Kucera H, Gaikwad NW. Prehispanic use of chili peppers in Chiapas, Mexico. PLoS One. 2013;8(11). DOI: 10.1371/journal.pone.0079013

[72] Gutiérrez-Carbajal MG, Monforte-González M, de Miranda-Ham ML, Godoy-Hernández G, Vázquez-Flota F. Induction of capsaicinoid synthesis in Capsicum Chinense cell cultures by salicylic acid or methyl jasmonate. Biologia Plantarum. 2010;54(3):430-434. DOI: 10.1007/ s10535-010-0078-z

[73] Giuffrida D, Zoccali M, Giofrè SV, Dugo P, Mondello L. Apocarotenoids determination in Capsicum Chinense Jacq. cv. Habanero, by supercritical fluid chromatography-triple-quadrupole/mass spectrometry. Food Chemistry. 2017;231:316-323. DOI: 10.1016/j. foodchem.2017.03.145 